UCRL-JC-123534

PREPRINT

CONF-9603/49--

\title{
First Flight of the Cloud Detection Lidar Instrument Package
}

J. R. Henderson, A. G. Ledebuhr, G. Cameron, P. Carter,

R. E. Hugenberger, J. F. Kordas, D. P. Nielsen, P. Stratton, B. Taylof C E IVED

APR 181996

OSTI

This paper was prepared for submittal to the Atmospheric Radiation Measurement Program Science Team Meeting

San Antonio, TX

March 4-7, 1996

March 1996

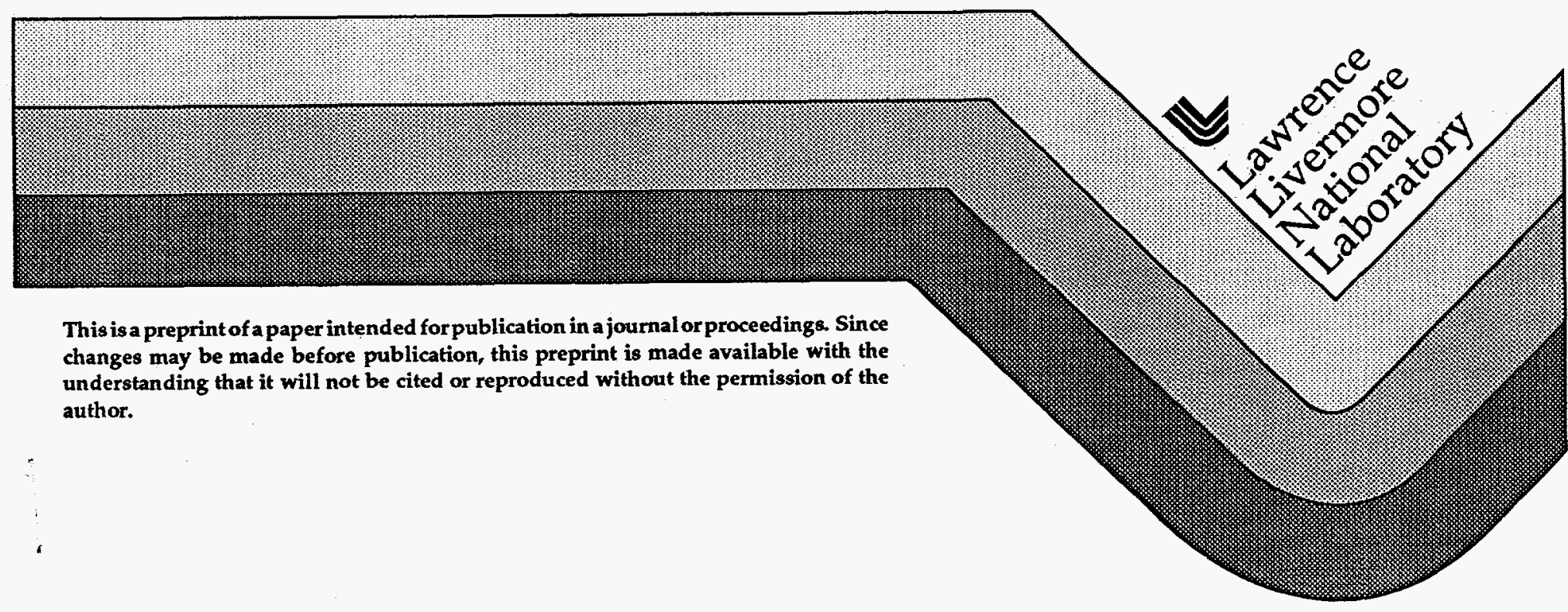




\section{DISCLAIMER}

This document was prepared as an account of work sponsored by an agency of the United States Government. Neither the United States Government nor the University of California nor any of their employees, makes any warranty, express or implied, or assumes any legal liability or responsibility for the accuracy, completeness, or usefuiness of any information, apparatus, product, or process disclosed, or represents that its use would not infringe privately owned rights. Reference herein to any specific commercial products, process, or service by trade name, trademark, manufacturer, or otherwise, does not necessarily constitute or imply its endorsement, recommendation, or favoring by the United States Govemment or the University of California. The views and opinions of authors expressed herein do not necessarily state or reflect those of the United States Government or the University of California, and shall not be used for advertising or product endorsement purposes. 


\title{
First Flight of the Cloud Detection Lidar Instrument Package
}

\author{
John R. Henderson, Arno G. Ledebuhr, George Cameron, \\ Preston Carter, Robert E. Hugenberger, Joe F. Kordas, \\ Darron P. Nielsen, Paul Stratton, and Bill Taylor
}

\author{
Physics and Space Technology \\ Lawrence Livermore National Laboratory \\ Livermore, California 94550
}

The Cloud Detection Lidar Instrument Package is composed of three instruments: the Cloud Detection Lidar (CDL) and two Wide Field of View (WFOV) cameras. The CDL can be rotated to operate in either a nadir-looking or zenith-looking mode. The WFOV cameras provide imagery to complement the CDL measurements. One camera is fixed at nadir looking and the other at zenith looking. Only one camera may be operational at a time. All instruments were successfully flown in September-November 1995.

\section{The Instruments}

The function of the CDL is the detection and profiling of high altitude thin cirrus clouds. It is designed to profile to $20 \mathrm{~km}$ range with a selectable range resolution down to 50 meters. The CDL detects clouds and aerosols by their backscatter return from an outgoing laser pulse.

The CDL has a mass of $28 \mathrm{~kg}$, consumes 100 watts of power, and occupies $<0.1$ cubic-meters of volume. The main sensor assembly contains a laser diodepumped Nd:YLF laser with an output wavelength of $1.053 \mu \mathrm{m}$ and operating at $5 \mathrm{kHz}$ repetiton rate with Q-switched $20 \mathrm{~ns}$ long pulses of $48 \mu \mathrm{J} /$ pulse. A single-photon counting Geiger-mode avalanche photodiode (APD) detector is used to detect the return signal. A stacked narrow bandpass interference filter and etalon combination generate a $0.1 \mathrm{~nm}$ wide filter with over $35 \%$ in-band transmission. The amplitude of the return signal provides information on the cloud/aerosol density or ground albedo. The return amplitudes are binned in 200 range bins. (The number of range bins is set by the programming to a maximum of 1024.) The distance per range bin is userselectable in multiples of $50 \mathrm{~m}$. Typically $100 \mathrm{~m}$ is used, giving a detection range to $20 \mathrm{~km}$. A background bin equivalent to $5 \mathrm{~km}$ is acquired after the range bins. This is used to correct for background from ambient illumination. The range and background data are telemetered to the ground at one second intervals, along with a variety of housekeeping information used to monitor the instrument performance and status. Table 1 lists some of the parameters of the first flight instrument.

The LIDAR uses a common aperture $20 \mathrm{~cm}$-diameter telescope to output the transmitted beam and receive the backscattered radiation. The system is 
inherently eye-safe through a novel approach of operating with very low energy pulses expanded over the aperture of the telescope. Additional safety is provided by on-board interlocks and operational procedures. The system is designed to provide a measurement each second, so that the returns from 5000 separate shots are added up to increase the effective signal to noise.

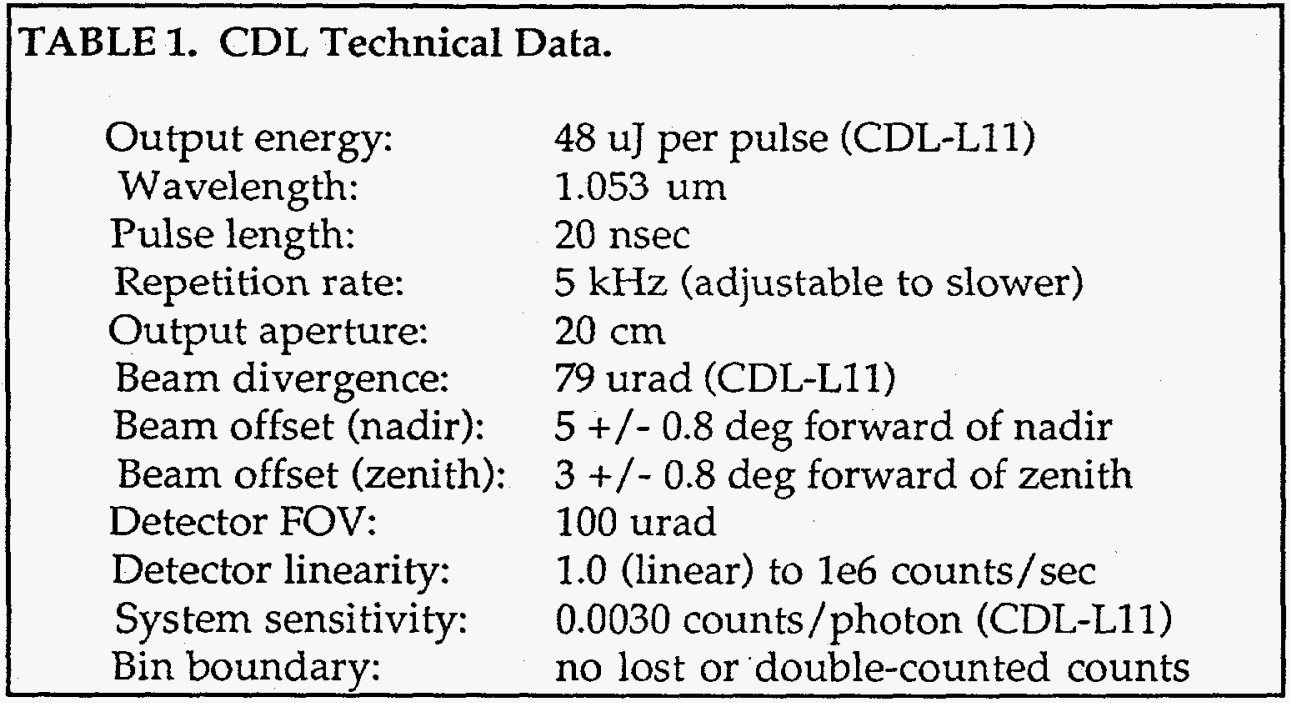

The WFOV cameras are nominally identical. Their purpose is to provide information on the type and extent of cloud cover as well as qualitative information on the type of ground cover being overflown. The CCD cameras give a $256 \times 256$ black and white image digitized at 8 bits. The cameras have automatic gain and offset control to maximize utility of the 8-bit range. The field of view is 29.3 degrees along track and 24.1 degrees across track (rectangular pixels). Exposure time can vary from 0.5 us to $20 \mathrm{~ms}$, and is short enough to avoid motion blurring of the image. Spectral response is from 350 $\mathrm{nm}$ to $1150 \mathrm{~nm}$, peaked at $650 \mathrm{~nm}$, with half-peak points at 420 and $830 \mathrm{~nm}$.

The WFOV optical design was intended to give overlapping imagery when flown on a UAV. The instrument was actually flown on the Grob Egrett, which has a higher ground speed and different altitude. Overlapping imagery was obtained for parts of many of the flights when there was sufficient headwind. Images are telemetered down every 65.5 seconds. The cameras share power, control, and communications with the CDL.

\section{Performance}

The standard mode of operating the instruments was to operate the CDL in zenith looking mode for ascent, rotate to nadir looking mode for the bulk of the flight, and then rotate to zenith looking mode for descent. The nadir camera was typically operated continuously throughout the flight. Data from the instruments was telemetered to the ground and recorded there. Control 
commands from the ground were automated for later flights to execute the sequence above. This gave the maximum nadir looking CDL data and minimized the non-operational time during CDL rotation. There were no problems with CDL rotation despite the instrument bay temperatures being lower than expected.

Data loss for the CDL was a few percent, most of which occurred during turns where the data is of less scientific interest. The vast majority of data gaps are of a single one second data record. This has little scientific impact. During the first flight, the instrument bay temperature dropped below the operational limits and the interlocks shut the instrument off. This problem was fixed and never recurred. The range data agreed well with the radar data and pilot reports of cloud altitudes. The ground returns agreed with the reported altitudes. Detection of sub-visual cirrus was demonstrated on October 24, 1995 when the CDL had been detecting cirrus for 10's of seconds, the pilot reported cirrus ahead and the CDL signal jumped a factor of five when the visual cirrus was overflown.

The CDL was designed to have sufficient sensitivity to detect a $100 \mathrm{~m}$ thick thin cirrus cloud of opacity 0.03 at a distance of $20 \mathrm{~km}$. For the above flight, the instrument sensitivity was estimated by plotting a histogram of ground return signal against cloud return signal. In the limit of low opacity, there is a linear relation between the two return signals. This gives a noise-equivalent opacity of $8.2 \times 10^{-4}$. Scaling the cloud distance from $2.5 \mathrm{~km}$ to $20 \mathrm{~km}$, and the cloud thickness from $382 \mathrm{~m}$ (effective) to $100 \mathrm{~m}$, the noise-equivalent detectable opacity is 0.014 . For most of the September 29, 1995 flight, the CDL detected low clouds at $12.4 \mathrm{~km}$ range $(\sim 1.4 \mathrm{~km} \mathrm{MSL})$ and variable ground returns. A histogram analysis covering the non-linear region (clear skies to no ground return) gives a noise-equivalent detectable opacity is 0.014 , identical to the thin cirrus results. This is two times better than the design specification.

The WFOV cameras were of great interest during the flight. They are invaluable for real time data analysis since they give immediate information on presence and extent of cloud cover. The cameras worked reliably during all flying conditions, including the low instrument bay temperatures. Approximately half of the images were corrupted by telemetry problems. Approximately one-third of the corrupt images could be repaired by inspecting the image to determine dropout location, and adding pixels to repair the defect. The value of the added pixels is determined by neighbor averaging. The format of the WFOV image transmission has been changed to isolate the effects of telemetry errors. We expect that the next flight series will have only a few percent of the images lost or noticeably corrupted. Under certain lighting conditions, the CCD generates a vertical stripe on the image. This is easily removed in post processing and typically leaves no noticeable artifacts. 


\section{Results}

Figure 1 shows the CDL results for part of the 30-Oct-95 flight. Data before and after instrument rotation are shown. There is a high thin cirrus layer and an opaque low cloud layer. Figure 1 has been thresholded for printing purposes. The raw data and color plots show much greater information about cloud structure and the extent of thin cloud features. For elevation plots, the CDL range data is converted to aerosol elevation data by utilizing data from other instruments to correct for the aircraft attitude and altitude. The ground return signals come out at the correct altitude for both level flight and turns, validating the range-to-altitude conversion algorithms.

Figure 2 shows a WFOV image showing broken clouds, the ground, and the cloud shadows on the ground.

A cloudiness indicator "cloudy" is derived from the CDL data by picking the largest return signal in the $0.6 \mathrm{~km}$ to $20 \mathrm{~km}$ elevation range for each one second record. This indicator can be used in a quantitative manner to estimate cloud opacity and the likelihood of ground radiation passing through the cloud.

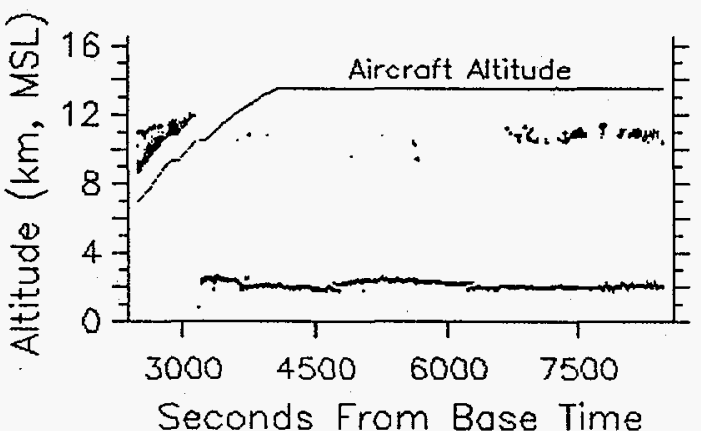

Figure 1. 30-Oct-95 CDL data converted to elevations. The data have been summed to 20 second intervals. The points displayed are range bins with a $S / N$ greater than 10 . The upper line is the aircraft altitude. Note that the cirrus at $11 \mathrm{~km}$ are detected from below before 3175 seconds and from above after 3640 seconds. The clouds at 2 $\mathbf{k m}$ are only detected from above in this plot. Down-to-up rotation took 55 seconds.

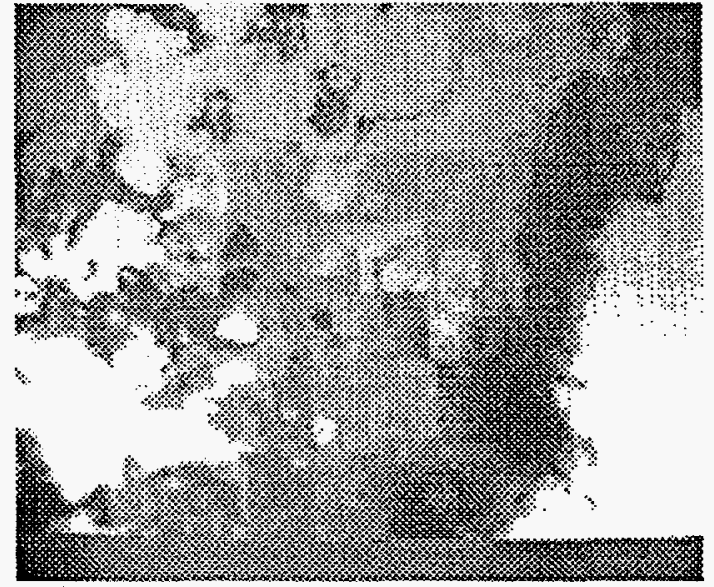

Figure 2. Nadir WFOV image showing the ground, clouds, cloud structure, and cloud shadows. The band across the lower edge of the image is the window edge of the instrument bay. The cloud shadows are about $1 / 4$ frame "above" the clouds in this image. (29Sep95, 18:13:16 GMT.)

\section{Acknowledgments}

This work was performed under the auspices of the U. S. Department of Energy by Lawrence Livermore National Laboratory under contract No. W7405-Eng-48. 


\section{DISCLAMMER}

Portions of this document may be illegible in electronic image products. Images are produced from the best available original document. 